\title{
Effects of Acute Blood Volume Expansion on Respiratory Mechanics in the Rat
}

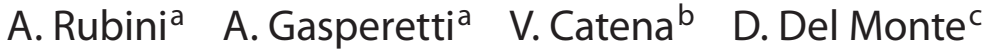 \\ aDepartment of Human Anatomy and Physiology, Physiology Section, University of Padova, \\ ${ }^{\mathrm{b}}$ Department of Anesthesiology and Intensive Care, ULSS 3, Bassano del Grappa, and \\ 'Department of Anesthesiology and Intensive Care, ULSS 15, Camposampiero, Italy
}

\section{Key Words}

Blood volume expansion - End-inflation occlusion method • Respiratory mechanics - Respiratory system hysteresis •

Work of breathing

\begin{abstract}
Backgrounds: The effects of acute blood volume expansion (BVE) on the respiratory mechanics of normal animals have been not extensively studied. The subject is of both theoretical and practical interest since BVE is a frequent medical intervention, and the associated increase in cardiac output may occur in different physiopathological situations. Objectives: To describe the changes in the parameters of respiratory mechanics occurring as an effect of acute BVE and the related increase in cardiac output. Methods: We applied the end-inflation occlusion method in normal, positive pressure-ventilated rats to measure the respiratory mechanics under control and BVE conditions. Results: Under BVE conditions, we found a statistically significant increase in static respiratory system elastance $\left(E_{s t, r s}\right)$, ohmic airway resistance plus resistance of respiratory system tissues to movement $\left(R_{\text {min,rs }}\right)$, and overall resistance including pendelluft and stress relaxation effects $\left(R_{\text {max,rs }}\right)$. Under BVE conditions, the resistive component due to sole stress relaxation and pendelluft $\left(R_{\text {visc,rs }}\right)$ increased almost significantly while a significant increment in mean respiratory system hysteresis sur-
\end{abstract}

face area $\left(\mathrm{Hy}_{\mathrm{rs}}\right)$ was also found. Conclusions: Increasing pulmonary blood flow by BVE increases the mechanical work of breathing because of the effects on $E_{s t, r s}, R_{\min , r s}$ and $R_{\max , r s}$ and because of the increase in $\mathrm{Hy}_{\mathrm{rs}}$.

Copyright $\odot 2009$ S. Karger AG, Basel

\section{Introduction}

The mechanical characteristics of lung tissue may change as a consequence of variations in pulmonary blood volume. In particular, an increase in pulmonary blood volume is expected to increase lung stiffness, and airway resistance might increase as a consequence of blood engorgement. A modification of cardiac output is thus expected to modify the respiratory system mechanics because of the associated effects on pulmonary blood volume. The latter should increase with cardiac output because of the high distensibility of pulmonary blood vessels, and/or their possible recruitment.

This aspect has been studied mainly in infants with various congenital heart defects causing different ratios of pulmonary to systemic blood flow [1-5], and in infants after surgical correction of left to right shunts $[6,7]$, after induction of a left to right shunt [8], or correction of pulmonary hyper- or hypoperfusion [9]. The results of these studies suggest that a high pulmonary blood flow may be

\section{KARGER}

Fax +4161306 1234

E-Mail karger@karger.ch

www.karger.com (c) $2009 \mathrm{~S}$. Karger AG, Basel

0025-7931/10/0796-0497\$26.00/0

Accessible online at:

www.karger.com/res
Alessandro Rubini

Department of Human Anatomy and Physiology

Physiology Section, University of Padova, Via Marzolo 3

IT-35100 Padova (Italy)

Tel. +39 049827 5310, Fax +39 049827 5301, E-Mail alessandro.rubini@unipd.it 
associated with increased pulmonary elastance and airway resistance $[10,11]$.

However, previously reported investigations compared data obtained before and after highly invasive, open-chest surgical interventions. Moreover, due to the chronic pathological circulatory conditions of the subjects, unknown effects of possible chronic modifications of the pulmonary parenchyma and/or vasculature could not be excluded.

Since there are no data on the possible effects of changes in cardiac output on respiratory mechanics in controlled, acute, minimally invasive laboratory experiments in healthy animals, we carried out such a study in rats before (control) and after blood volume expansion (BVE).

Respiratory mechanics were studied with the technique of rapid end-inflation airway occlusion during constant-flow inflation which, differently from most other previously used techniques, models the respiratory system as composed by two compartments. It has been used in many studies of respiratory mechanics both in humans [12-15] and experimental animals [16-18], but has never been used previously to study this subject.

No evidence exists in the literature about the possible effect of a change in pulmonary blood volume and cardiac output on the hysteresis of the respiratory system. The work of breathing (WOB) has never been measured in rats during positive-pressure inflation. Thus, we measured the effects of BVE on both total WOB $\left(\mathrm{WOB}_{\text {tot }}\right)$ and its elastic $\left(\mathrm{WOB}_{\mathrm{el}}\right)$ and resistive $\left(\mathrm{WOB}_{\mathrm{res}}\right)$ components, and on respiratory system hysteresis $\left(\mathrm{Hy}_{\mathrm{rs}}\right)$.

\section{Materials and Methods}

The experiments were carried out on 12 consecutive Wistar albino rats, 6 males and 6 females (weight $318 \pm 18$ g, mean \pm $\mathrm{SD})$. The experiments were performed according to the Declaration of Helsinki and the European laws on animal experimentation $(86 / 609 / \mathrm{EEC})$. The experimental protocol was approved by the local Ethical Committee.

The rats were anesthetized by intraperitoneal injection of chloral hydrate $(400 \mathrm{mg} / \mathrm{kg})$, the anesthesia level being monitored by observing the suppression of the corneal reflex and checking the presence of spontaneous breathing.

Heart rate was measured with ECG probes positioned on the limbs of the rats.

The rats were trachetomized, and a small polyethylene catheter ( $2 \mathrm{~mm}$ inner diameter, $3.5 \mathrm{~cm}$ long) was inserted through an incision performed on the second tracheal ring, and held tightly in place. The tracheal cannula was connected to a mechanical ventilator (Rodent Ventilator 7025, Basile, Italy) set to deliver a tidal volume (VT) of $3 \mathrm{ml}$ at a breathing frequency of 100 breaths per minute. Mechanical ventilation was kept constant throughout the duration of the experiment, apart from the short time necessary for the constant-flow inflation tests needed for measuring respiratory mechanics and hysteresis (about $2 \mathrm{~min}$ each).

A small polyethylene cannula $(24 \mathrm{G})$ was inserted into the right femoral vein, carefully advanced about $1 \mathrm{~cm}$, and firmly held in place. The femoral cannula was connected to a waterfall salinefilled system to allow the measurement of systemic venous pressure $\left(\mathrm{P}_{\mathrm{v}}\right)$. Care was taken to avoid air bubbles entering the venous system.

The rats were paralyzed by an intravenous injection of cisatracurium $(0.4 \mathrm{mg} / \mathrm{kg})$, which is known not to substantially modify the heart rate [19], as opposed to other paralyzing drugs. Additional doses of cis-atracurium were occasionally administered when needed, as indicated by the onset of spontaneous breathing.

During the constant-flow inflation tests, the ventilator was disconnected, and the tracheal cannula connected to a constantflow pump (SP 2000 Series Syringe Pump sp210iw; World Precision Instruments, USA) set to deliver a VT of $3 \mathrm{ml}$ with a (nearly) square wave flow (F) of $4 \mathrm{ml} / \mathrm{s}$. The time for the rise and fall of flow was about $30 \mathrm{~ms}$. The precision of the pump settings was accurately checked before the experiments.

The lateral tracheal pressure proximal to the tracheal cannula was monitored (142 pc 01d; Honeywell, USA) and continuously recorded (1326 Econo Recorder, Biorad, Italy).

The end-inflation occlusion method $[12,13]$ was applied to measure respiratory mechanics: static elastic pressure of the respiratory system $\left(\mathrm{P}_{\mathrm{el}, \mathrm{rs}}\right)$, total resistive pressure drop $\left(\mathrm{P}_{\max , \mathrm{rs}}\right)$ and the sudden Newtonian resistive pressure drop on flow interruption $\left(\mathrm{P}_{\mathrm{min}, \mathrm{rs}}\right)$ were measured on adequately magnified tracings (fig. 1). $\mathrm{P}_{\max , \mathrm{rs}}$ was measured as the difference between the maximum value of pressure at end inflation $\left(\mathrm{P}_{\mathrm{dyn}, \max }\right)$ and $\mathrm{P}_{\mathrm{el}, \mathrm{rs}} . \mathrm{P}_{\mathrm{min}, \mathrm{rs}}$ was measured as the difference between $P_{d y n, m a x}$ and $P_{1}$, the pressure value measured immediately after flow interruption (fig. 1).

As previously stated $[12,13,16,17], \mathrm{P}_{\text {min,rs }}$ represents the resistive Newtonian pressure drop which would theoretically occur at infinite breathing frequency, i.e. without the pressure drop due to mechanical uneveness within the system and to stress relaxation, which are instead included in $\mathrm{P}_{\max , \mathrm{rs}}$.

Mean pressure data obtained from 3-5 inflations for each rat allowed the calculation of the respiratory system static elastance $\left(\mathrm{E}_{\mathrm{st}, \mathrm{rs}}=\mathrm{P}_{\mathrm{el}, \mathrm{rs}} / \mathrm{VT}\right)$ and respiratory system total resistance $\left(\mathrm{R}_{\text {max }, \mathrm{rs}}=\mathrm{P}_{\text {max }, \mathrm{rs}} / \mathrm{F}\right)$ which, together with the Newtonian inspiratory airflow resistance provided by the airways and the respiratory system tissues $\left(\mathrm{R}_{\min , \mathrm{rs}}=\mathrm{P}_{\text {min,rs }} / \mathrm{F}\right)$, includes the pressure drop due to uneven intrapulmonary airflow distribution and to the effect of stress relaxation. This last component of $R_{\max , r s}$ was isolated and quantified as 'viscous' resistance $\left(\mathrm{R}_{\mathrm{visc}, \mathrm{rs}}=\mathrm{R}_{\max , \mathrm{rs}}\right.$ $\left.\mathrm{R}_{\text {min,rs }}\right)$.

After these measurements of respiratory mechanics, which took about $2 \mathrm{~min}$, mechanical ventilation was restored and maintained for $5 \mathrm{~min}$. After this, in order to obtain a constant volume history for the measurement of respiratory system hysteresis, the lungs were consecutively inflated three times with a $10-\mathrm{ml}$ syringe up to a static elastic pressure of $20-25 \mathrm{~cm} \mathrm{H}_{2} \mathrm{O}$. The respiratory system was then inflated in five 1-ml steps with a precision glass syringe starting from functional residual capacity and then deflated in a similar manner. The pertinent static elastic pressures were measured with a water-filled manometer, and the static inflation-deflation volume-pressure curves obtained. The hystere- 


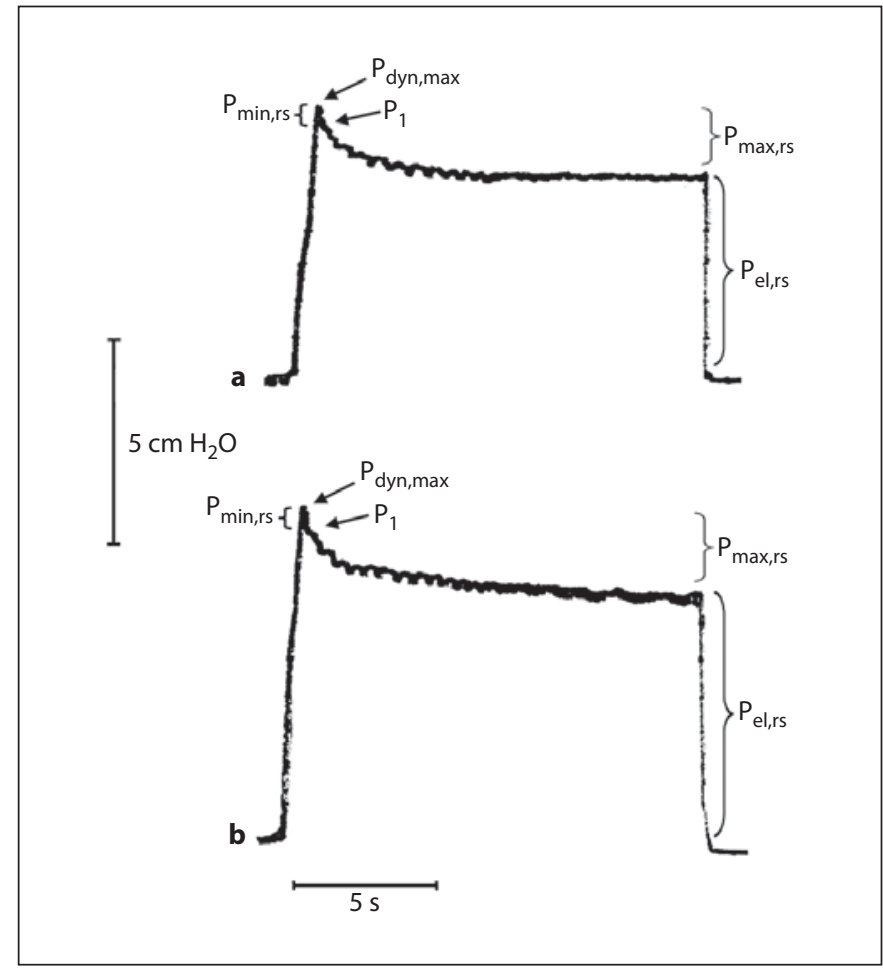

Fig. 1. Representative tracings of lateral tracheal pressure on flow interruption. Tracings of recorded lateral tracheal pressure are shown for the control (a, upper panel) and BVE (b, lower panel) conditions in the same rat. The relevant pressures used for the calculations of respiratory system mechanics are indicated (symbols are explained in the text). Cardiac artifacts are also evident.

sis areas $\left(\mathrm{Hy}_{\mathrm{rs}}\right)$ were quantified and expressed in $\mathrm{cm} \mathrm{H}_{2} \mathrm{O} \cdot \mathrm{ml}$. The areas were determined by plotting them on a paper of known weight, and subsequently weighing the paper encompassing the hysteresis areas.

After ventilation was restored, BVE was induced by an intravenous infusion of $2.5 \mathrm{ml}$ of a plasma expander solution (Voluven $^{\circledR}$ ) containing $6 \%$ hydroxyethylic starch in saline (osmotic pressure $308 \mathrm{mosm} / \mathrm{l}$ ) in about $3 \mathrm{~min}$. It may be estimated that this infusion increased the circulating blood volume by about $15-18 \%$, roughly corresponding to the infusion of about 1 liter of blood in humans. Venous pressure and heart rate were again measured (BVE values), and measurements of respiratory mechanics repeated as described above.

After this, the lungs were carefully dissected and weighed. The lungs were then subjected to a constant dry air flow for $24 \mathrm{~h}$ through the tracheal cannula, and weighed again. The weight of the cannula was subtracted from wet and dry weights, and the net wet to dry ratios of the lungs calculated. Prolonging the drying time for an additional $8 \mathrm{~h}$ did not modify the results.

The equipment resistance, including the tracheal cannula and a standard three-way stop-cock, was separately measured at a flow of $4 \mathrm{ml} / \mathrm{s}$ and amounted to $0.0575 \mathrm{~cm} \mathrm{H} \mathrm{H}_{2} \mathrm{O} / \mathrm{ml} \cdot \mathrm{s}^{-1}$. $\mathrm{R}_{\mathrm{eq}}$ was subtracted from results, which hence represent intrinsic values.

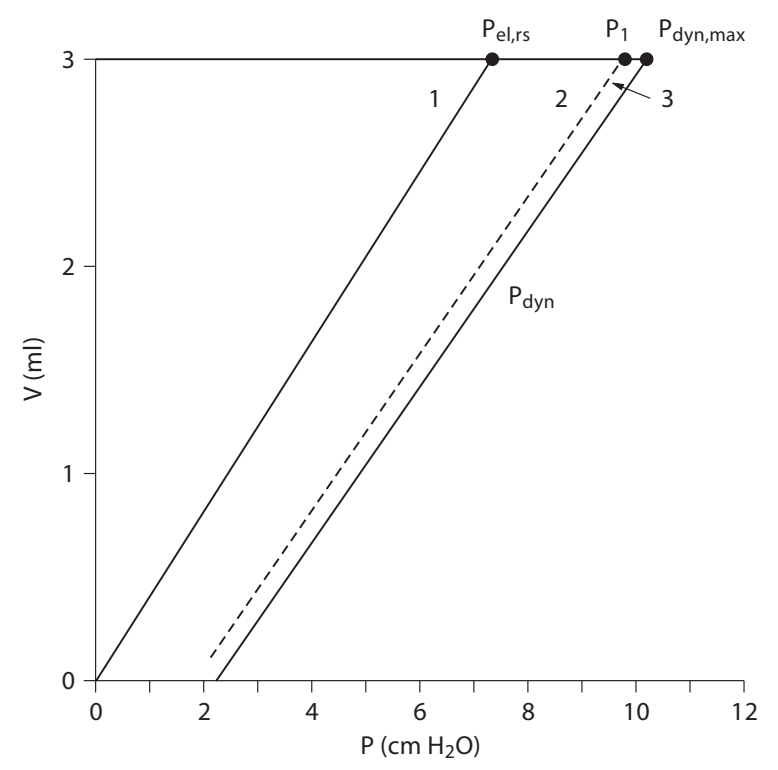

Fig. 2. Schematic drawning of the P/V relationship during constant-flow inflation and flow interruption. Area 1 represents $\mathrm{WOB}_{\mathrm{el}}$ while areas $2+3$ represent $\mathrm{WOB}_{\text {res }}$. $\mathrm{WOB}_{\mathrm{el}}+\mathrm{WOB}_{\text {res }}=$ $\mathrm{WOB}_{\text {tot }}$. Area 3 represents $\mathrm{WOB}_{\text {ohm }}$, to overcome the ohmic airway resistance plus the viscous resistance to the movement opposed by the lungs and chest wall tissues. $\mathrm{WOB}_{\text {res }}-\mathrm{WOB}_{\mathrm{ohm}}=$ $\mathrm{WOB}_{\mathrm{visc}}$, the mechanical work done to overcome the resistive effects of stress relaxation and pendelluft.

WOB values were calculated according to the literature $[15,20]$ as described in figure 2 . We calculated $\mathrm{WOB}_{\text {tot }}$ by measuring the surface areas delimited by the total pressure $\left(\mathrm{P}_{\text {dyn }}\right)$ tracings from which the resistive pressure due to the tracheal cannula was subtracted. $\mathrm{WOB}_{\mathrm{el}}$ was obtained on the same diagram as the areas encompassing the static pressure/volume lines. $\mathrm{WOB}_{\text {res }}$ was obtained by subtraction: $\mathrm{WOB}_{\text {res }}=\mathrm{WOB}_{\text {tot }}-\mathrm{WOB}_{\mathrm{el}}$. $\mathrm{WOB}_{\text {res }}$ was also partitioned in the resistive work done to overcome ohmic airway resistance and respiratory system tissue movements $\left(\mathrm{WOB}_{\mathrm{ohm}}\right)$ and the resistive work done to overcome the effects of pendelluft and stress relaxation $\left(\mathrm{WOB}_{\mathrm{visc}}\right) . \mathrm{WOB}_{\mathrm{ohm}}$ was calculated as the area comprised between $\mathrm{P}_{\mathrm{dyn}}$ and $\mathrm{P}_{1}$ lines, where $\mathrm{P}_{1}$ is the pressure value immediately after flow interruption (fig. 1, 2). $\mathrm{WOB}_{\text {visc }}$ was calculated by subtraction as $\mathrm{WOB}_{\mathrm{visc}}=\mathrm{WOB}_{\text {res }}-$ $\mathrm{WOB}_{\mathrm{ohm}}$. These calculations were obtained for each rat, both under control and BVE conditions, and the mean values statistically compared.

All measured variables were normally distributed (SmirnovKolmogorov test). On this basis, each rat being its own control, statistical analysis of the differences between control and BVE conditions was performed by Student's t test for paired data. All values are expressed as means \pm SE $(n=12)$. 
Fig. 3. Heart rate and $\mathrm{P}_{\mathrm{v}}$. Mean values $( \pm$ $\mathrm{SE}, \mathrm{n}=12)$ of heart rate $(\mathrm{HR}, \mathbf{a})$ and femoral vein pressure $\left(\mathrm{P}_{\mathrm{v}}, \mathbf{b}\right)$ under control and BVE conditions. Statistical significances of the differences are also indicated.
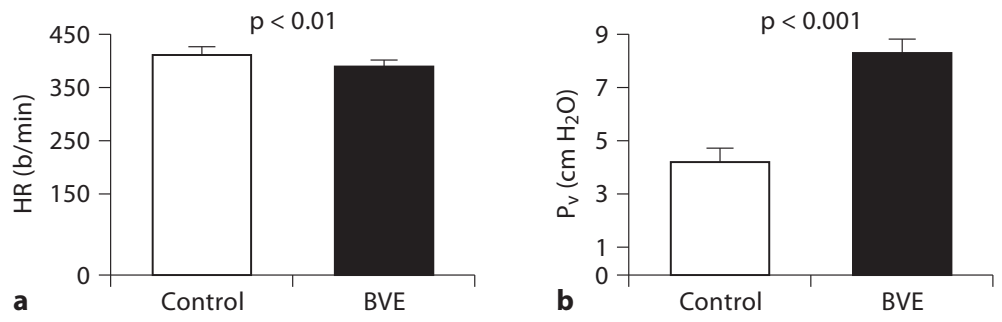

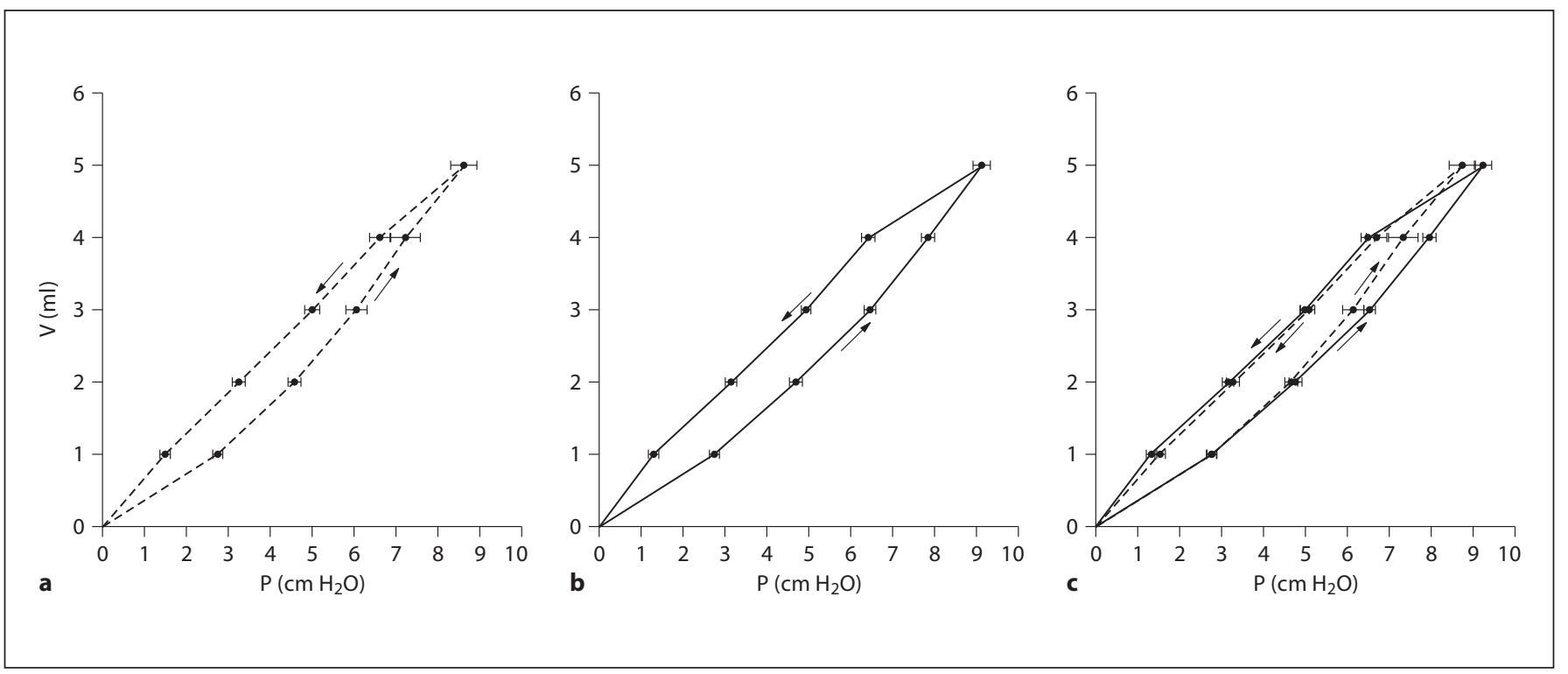

Fig. 4. $\mathrm{P} / \mathrm{V}$ hysteresis loops. Mean $( \pm \mathrm{SE}, \mathrm{n}=12) \mathrm{V}-\mathrm{P}$ loops describing $\mathrm{Hy}_{\mathrm{rs}}$ under the control (a) and BVE $(\mathbf{b})$ conditions. In order to demonstrate the increase in $\mathrm{Hy}_{\mathrm{rs}}$ under the BVE condition, the curves are superimposed in $\mathbf{c}$.

Table 1. Mean respiratory mechanics under the control and BVE conditions $( \pm \mathrm{SE}, \mathrm{n}=12)$

\begin{tabular}{|c|c|c|c|}
\hline & Control & BVE & $\mathrm{p}$ \\
\hline $\mathrm{E}_{\mathrm{st}, \mathrm{rs}}, \mathrm{cm} \mathrm{H}_{2} \mathrm{O} / \mathrm{ml}$ & $2.4 \pm 0.11$ & $2.6 \pm 0.1$ & $<0.05$ \\
\hline $\mathrm{R}_{\max , \mathrm{rs}}, \mathrm{cm} \mathrm{H}{ }_{2} \mathrm{O} / \mathrm{ml} \cdot \mathrm{s}^{-1}$ & $0.66 \pm 0.04$ & $0.75 \pm 0.04$ & $<0.05$ \\
\hline $\mathrm{R}_{\min , \mathrm{rs}}, \mathrm{cm} \mathrm{H}_{2} \mathrm{O} / \mathrm{ml} \cdot \mathrm{s}^{-1}$ & $0.06 \pm 0.008$ & $0.09 \pm 0.008$ & $<0.001$ \\
\hline $\mathrm{R}_{\mathrm{visc}, \mathrm{rs}}, \mathrm{cm} \mathrm{H} \mathrm{H}_{2} \mathrm{O} / \mathrm{ml} \cdot \mathrm{s}^{-1}$ & $0.59 \pm 0.045$ & $0.65 \pm 0.035$ & 0.07 \\
\hline $\mathrm{P}_{\text {dyn,max }}, \mathrm{cm} \mathrm{H}_{2} \mathrm{O}$ & $9.78 \pm 0.5$ & $11 \pm 0.4$ & $<0.05$ \\
\hline $\mathrm{P}_{1}, \mathrm{~cm} \mathrm{H}_{2} \mathrm{O}$ & $9.55 \pm 0.45$ & $10.6 \pm 0.4$ & $<0.05$ \\
\hline $\mathrm{P}_{\mathrm{el}, \mathrm{rs}}, \mathrm{cm} \mathrm{H} \mathrm{H}_{2} \mathrm{O}$ & $7.2 \pm 0.3$ & $8 \pm 0.3$ & $<0.05$ \\
\hline
\end{tabular}

Table 2. Mean values of different components of inspiratory WOB ( $\pm \mathrm{SE}, \mathrm{n}=12, \mathrm{~cm} \mathrm{H} \mathrm{H}_{2} \mathrm{O} \cdot \mathrm{ml}$ ) under the control and BVE conditions

\begin{tabular}{lrrr}
\hline & \multicolumn{1}{c}{ Control } & \multicolumn{1}{c}{ BVE } & \multicolumn{1}{c}{$\mathrm{p}$} \\
\hline WOB $_{\text {tot }}$ & $17.9 \pm 0.8$ & $21 \pm 0.8$ & $<0.01$ \\
$\mathrm{WOB}_{\text {el }}$ & $9.6 \pm 0.4$ & $11.6 \pm 0.4$ & $<0.01$ \\
$\mathrm{WOB}_{\text {res }}$ & $8.2 \pm 0.5$ & $9.3 \pm 0.4$ & $<0.05$ \\
$\mathrm{WOB}_{\text {ohm }}$ & $0.74 \pm 0.1$ & $1.15 \pm 0.1$ & $<0.01$ \\
$\mathrm{WOB}_{\text {visc }}$ & $7.4 \pm 0.4$ & $8.2 \pm 0.4$ & 0.07 \\
\hline
\end{tabular}


Fig. 5. Mean values ( $\pm \mathrm{SE}, \mathrm{n}=12$ ) of $\mathrm{Hy}_{\mathrm{rs}}$ under control and BVE conditions. Statistical significance of the difference is also indicated.

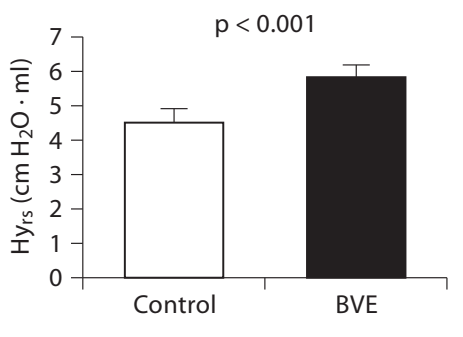

Table 3. Mean values $( \pm \mathrm{SE}, \mathrm{n}=12)$ of $\mathrm{P}_{\mathrm{el}, \mathrm{rs}}\left(\mathrm{cm} \mathrm{H}_{2} \mathrm{O}\right)$ during stepwise inflation and deflation of the respiratory system

\begin{tabular}{|c|c|c|c|c|c|c|}
\hline \multirow[t]{2}{*}{ V } & \multicolumn{2}{|l|}{ Control } & \multirow[t]{2}{*}{$\mathrm{p}$} & \multicolumn{2}{|l|}{ BVE } & \multirow[t]{2}{*}{$\mathrm{p}$} \\
\hline & inflation & deflation & & inflation & deflation & \\
\hline $1 \mathrm{ml}$ & $2.7 \pm 0.1$ & $1.5 \pm 0.1$ & $<0.001$ & $2.8 \pm 0.1$ & $1.35 \pm 0.1$ & $<0.001$ \\
\hline $2 \mathrm{ml}$ & $4.6 \pm 0.2$ & $3.3 \pm 0.1$ & $<0.001$ & $4.8 \pm 0.2$ & $3.2 \pm 0.1$ & $<0.001$ \\
\hline $3 \mathrm{ml}$ & $6.1 \pm 0.3$ & $5.1 \pm 0.2$ & $<0.001$ & $6.5 \pm 0.1$ & $5 \pm 0.1$ & $<0.001$ \\
\hline $4 \mathrm{ml}$ & $7.3 \pm 0.35$ & $6.7 \pm 0.25$ & $<0.001$ & $7.9 \pm 0.2$ & $6.5 \pm 0.1$ & $<0.001$ \\
\hline $5 \mathrm{ml}$ & $8.7 \pm 0.3$ & - & - & $9.25 \pm 0.2$ & - & - \\
\hline
\end{tabular}

\section{Results}

The results are reported in figures $3-5$ and in tables $1-3$.

On BVE, heart rate decreased from $411 \pm 14$ to $389 \pm$ 12 beats/min, and femoral vein pressure increased from $4.2 \pm 0.55$ to $8.3 \pm 0.52 \mathrm{~cm} \mathrm{H}_{2} \mathrm{O}$, both changes being significant (fig. 3).

We also observed an increase in $\mathrm{E}_{\mathrm{st}, \mathrm{rs}}, \mathrm{R}_{\min , \mathrm{rs}}$ and $\mathrm{R}_{\max , \mathrm{rs}}$, and the increase in $\mathrm{R}_{\mathrm{visc}, \mathrm{rs}}$ was almost significant $(\mathrm{p}=0.07$, table 1$)$.

Table 1 also reports the mean values of $\mathrm{P}_{\mathrm{dyn}, \max }, \mathrm{P}_{1}$ and $\mathrm{P}_{\mathrm{el}, \mathrm{rs}}$ measured under control and BVE conditions. Under the latter condition, all parameters increased significantly.

The values of $\mathrm{WOB}_{\text {tot }}$ and its components are reported in table 2. Under the BVE condition, we found a significant increase in $\mathrm{WOB}_{\text {tot }}, \mathrm{WOB}_{\mathrm{el}}$, $\mathrm{WOB}_{\text {res }}$ and $\mathrm{WOB}_{\text {ohm }}$, and the increase in $\mathrm{WOB}_{\text {visc }}$ was almost significant $(\mathrm{p}=$ 0.07).

The mean values of $\mathrm{P}_{\mathrm{el}, \mathrm{rs}}$ after 1-ml stepwise inflations and deflations are reported in table 3, both under control conditions and after acute BVE. The mean values at any volume were statistically different during inflation compared to deflation, indicating the presence of hysteresis both under control and BVE conditions. As shown in figures 4 and $5, \mathrm{Hy}_{\mathrm{rs}}$ under the BVE condition was significantly higher than under the control condition (5.8 \pm 0.37 vs. $\left.4.5 \pm 0.4 \mathrm{~cm} \mathrm{H}_{2} \mathrm{O} \cdot \mathrm{ml}, \mathrm{p}<0.001\right)$.

The $\mathrm{E}_{\text {st,rs }}$ values calculated from the stepwise-inflation pressure data in table 3 were similar to those obtained with the constant-flow occlusion technique reported in table 1.

The mean ratio of wet weight to dry weight was 4.05 $\pm 0.13(\mathrm{n}=12)$.

\section{Discussion}

The discussion includes the following separate points: technique, venous pressure and heart rate, $\mathrm{E}_{\mathrm{st}, \mathrm{rs}}, \mathrm{R}_{\mathrm{min}, \mathrm{rs}}$, $\mathrm{R}_{\mathrm{max}, \mathrm{rs}}$ and $\mathrm{R}_{\mathrm{visc}, \mathrm{rs}}, \mathrm{WOB}$, and $\mathrm{Hy}_{\mathrm{rs}}$.

\section{Technique}

The present experiments were designed to investigate the effects of acute BVE (and the associated increase in 
cardiac output, see below) on the mechanics of the respiratory system under minimally invasive and strictly controlled experimental conditions. In particular, surgical interventions were limited to the positioning of the tracheal and femoral vein cannulae, so that invasive maneuvers were kept to a minimum, leaving the cardiorespiratory system almost intact and without opening the chest wall.

This is different from previous investigations. The previous results were obtained mostly in children undergoing cardiac open-chest surgery, before and after highly invasive surgical maneuvers required to correct congenital heart defects [6-9]. Moreover, in our experiments, data were obtained from individual healthy rats under control conditions and immediately after acute BVE, so that each rat was its own control, and the possible confounding effects of chronic modifications of pulmonary parenchyma and/or vasculature were avoided. Other studies deal with different subjects presenting different ratios of pulmonary to systemic blood flow which had persisted for relatively long times [1-5].

Previous data were mostly obtained by means of different techniques based on single-compartment models, none by the constant-flow occlusion technique. Modeling the respiratory system as composed by two compartments allows to obtain both the ohmic airway resistance and the resistance of the respiratory system due to its viscoelastic properties and pendelluft [12-15].

For the constant-flow interruption technique to be ideally applied, the inflation flow should stop instantaneously, which in reality is not the case. A correction for this has been proposed, which renders the possible errors almost negligible [21]. We applied this correction to our data by manual extrapolation of the pressure tracings for the time necessary for a complete stop of the inspiratory flow, but the corrections were practically negligible, as previously reported in similar experiments in rats [18].

The wet to dry weight ratios we found are very similar to those reported in the literature for normal rats. A ratio of 4.3 was recently reported [22], which is even a little greater than the ratio we obtained. Thus, our results indicate that our rats did not develop substantial pulmonary fluid accumulation during the experiments. Visual inspection of the isolated lungs led to the same conclusion: absence of foam and no evidence of parenchymal fluid accumulation. Hence, our data compared control conditions against a higher cardiac output and pulmonary blood flow conditions in the absence of pulmonary edema, i.e., under physiological conditions.
We did not perform blood gas analyses, but pulmonary ventilation was kept constant throughout the experiments. Thus, it seems unlikely that changes in blood gases could have contributed to the observed differences between control and BVE conditions. It should be noted that an increase in cardiac output in the presence of constant pulmonary ventilation would eventually lead to a decrease in arterial $\mathrm{pO}_{2}$ and an increase in arterial $\mathrm{pCO}_{2}$. Although these possible changes may cause a decrease in airway resistance, an increment was in fact observed.

We have previously shown that circadian and estrous rhythms may significantly influence respiratory mechanics in the rat $[23,24]$. The possible effects of these variables on the present results were avoided because the measurements under control and BVE conditions were separated by a short time only.

\section{Venous Pressure and Heart Rate}

In order to avoid the effects of thoracotomy on respiratory mechanics, we measured the peripheral $\left(\mathrm{P}_{\mathrm{v}}\right)$ rather than the central venous pressure, before and after blood BVE. It is likely, however, that $P_{v}$ was a good index of the filling pressure of the heart chambers. As expected, our results show that the femoral vein pressure increased significantly following BVE (fig. 3b), suggesting that cardiac output and lung perfusion were substantially increased as a result of Starling's law of the heart.

A second indirect index of increased cardiac output is represented by the significant decrease in heart rate after BVE (fig. 3a). This is interpreted as a result of a baroreceptor-induced reflex elicited by increased systemic arterial pressure. Thus, since our rats exhibited bradycardia following BVE, they almost certainly had an increased mean arterial pressure secondary to increased cardiac output.

\section{Static Respiratory System Elastance}

The mean values of $E_{\text {st,rs }}$ obtained in the present study were similar to those previously reported in the literature in similar experiments. The reported mean values range between 1.75 and $5.5 \mathrm{~cm} \mathrm{H}_{2} \mathrm{O} / \mathrm{ml}$ [16, 18, 23-25].

We found a significant increase in $\mathrm{E}_{\mathrm{st}, \mathrm{rs}}$ as after BVE (and a related increase in lung perfusion). This is in line with a number of previous reports obtained under different experimental conditions $[1,2,4-6,8]$ and suggests that the amount of blood in the lungs has a substantial influence on tissue stiffness.

In contrast, Pellegrino et al. [26] found no change in respiratory system elastance after intravenous saline in- 
fusion $(30 \mathrm{ml} / \mathrm{kg})$ in healthy humans. Taking into account the normal distribution of intra- and extravascular fluids, it may be estimated that in the experiments of Pellegrino et al. the resulting BVE was not higher than 4-5\%, i.e. largely lower than that achieved in our experiments in the rat. Considering the normal rat blood volume and the fact that we used plasma as expander rather than saline, the achieved BVE in the present experiments may be estimated to be about $15-18 \%$. This is fairly similar to BVE in clinical practice after infusion of about 1 liter of plasma in humans. This BVE was high enough to substantially increase cardiac output in our rats, while this did certainly not happen to a similar degree in the experiments by Pellegrino et al. as also suggested by the constancy of arterial pressure values in their subjects before and after saline infusion.

Moreover, the increment in the volumes of liquid in the extravascular spaces of the lung parenchyma of the subjects of Pellegrino et al. was probably not sufficient to cause a detectable change in respiratory system elastance. Although the saline infusion rate in their experiments may be considered similar to that commonly used in clinical practice, it is largely lower than that used in similar experiments in the rat by Dellacà et al. [22], who in fact did observe an increase in respiratory system elastance due to a substantial fluid accumulation in the lungs. Pellegrino et al. did not report a direct quantitative estimation of fluid accumulation in the lung interstitium, but only an indirect estimation of airway edema.

Thus, the finding of Pellegrino et al. of no change in respiratory system elastance is probably due to a rather small increase in BVE and cardiac output, and an associated pulmonary vascular engorgement, and to a minor degree to fluid accumulation in the lung interstitium of their subjects. This was effective in increasing airway resistance, but not in changing respiratory system elastance.

The $\mathrm{E}_{\text {st,rs }}$ values measured with the constant-flow occlusion technique are very close to those calculated from the volume-pressure data reported in table 3 , obtained for the measurement of $\mathrm{Hy}_{\mathrm{rs}}$, which range from 1.7 to 2.8 $\mathrm{cm} \mathrm{H}_{2} \mathrm{O} / \mathrm{ml}$, depending on the volume of expansion of the respiratory system.

\section{Resistance of Respiratory System Tissues to Movement} (Ohmic Resistance)

Previously reported mean values of $\mathrm{R}_{\min , \mathrm{rs}}$ in similar experiments in the rat range from 0.037 to $0.4 \mathrm{~cm} \mathrm{H}_{2} \mathrm{O}$ / $\mathrm{ml} \cdot \mathrm{s}^{-1}[18,23-25]$, and our results are comprised in this range. They are near the lowest values previously report- ed, probably because of the lower inspiratory flow and greater VT we used in comparison with others. Our inspiratory flow was chosen according to Crosfill and Widdicombe [27]. Moreover, the mean weight of our rats is higher than that used by others, which ranges from 205 to $310 \mathrm{~g}$, and this also should cause a reduction in $\mathrm{R}_{\mathrm{min}, \mathrm{rs}}$ because of the increased lung volume.

It should be remembered that $\mathrm{R}_{\mathrm{min}, \mathrm{rs}}$ is a measure of the ohmic airway resistance plus the viscous resistance to the movement opposed by the lung and chest wall tissues, thus resembling a respiratory system resistance value [14].

$\mathrm{R}_{\text {min,rs }}$ was measured in a sole report [3] in infants but during expiratory flow interruption.

Previous and present data indicate that respiratory system resistance increases with increasing pulmonary blood flow. This has been attributed to a decrease in airway diameter [28], and the decreased air volume of the lungs may contribute.

\section{Overall Resistance Including Pendelluft and Stress}

Relaxation and Resistive Component due to Sole

\section{Stress Relaxation and Pendelluft}

Previously published works report $\mathrm{R}_{\text {max,rs }}$ values in normal rats comprised between 0.235 and $0.63 \mathrm{~cm} \mathrm{H}_{2} \mathrm{O}$ / $\mathrm{ml} \cdot \mathrm{s}^{-1}[16,18,23-25]$, and the values we report here are similar.

With increased pulmonary blood flow, an increment in $R_{\text {max,rs }}$ was found. $R_{v i s c, r s}$ was almost significantly increased as well ( $p=0.07)$, probably due to a lack of statistical power. These results are in agreement with Freezer al. [3], who reported similar conclusions although by a somewhat different experimental approach. Thus, stress relaxation and pendelluft appear to be influenced by pulmonary blood flow.

\section{Work of Breathing}

We were not able to find any published data describing the inspiratory WOB in the rat during positive-pressure inflation, nor could we find a description of the potential effects of BVE. According to our calculations, the mechanical work of inspiration increases in BVE with respect to control conditions (table 2). This is in agreement with the observed increases in $\mathrm{E}_{\mathrm{st}, \mathrm{rs}}$ for $\mathrm{WOB}_{\mathrm{el}}$ values, and of $\mathrm{R}_{\text {min,rs }}$ and $\mathrm{R}_{\text {max,rs }}$ for $\mathrm{WOB}_{\text {ohm }}$ and $\mathrm{WOB}_{\text {res }}$ values, respectively. As expected from the observed increment of $\mathrm{R}_{\mathrm{visc}, \mathrm{rs}}, \mathrm{WOB}_{\mathrm{visc}}$ mean values almost significantly increased $(p=0.07)$. 
Changes in respiratory system mechanics following BVE should cause an increase in WOB during spontaneous breathing too.

\section{Mean Respiratory System Hysteresis Surface Area}

We found a statistically significant increase of the respiratory system hysteresis in BVE compared to the control condition (fig. 4, 5). This means that pulmonary blood flow influences the hysteretic properties of the respiratory system. These represent a complex phenomenon, mainly due to the plastic characteristics of the tissue elements and to true tissue hysteresis, surface hysteresis linked to alveolar surfactant activity, differences in the sequences of recruitment and derecruitment of lung units between inflation and deflation.

Previous studies measuring hysteresis in the isolated rat lung for the same lung volume expansions as those performed here report values comprised between 2.49 and $4.45 \mathrm{~cm} \mathrm{H}_{2} \mathrm{O} \cdot \mathrm{ml}[23,24]$. The present data are somewhat higher (fig. 4), thus suggesting that chest wall hysteresis is not negligible in the rat, as previously reported for the dog [29].

We previously demonstrated an increment in lung hysteresis in a rat model of (static) pulmonary vascular engorgement [30]. We cannot exclude that a change in pulmonary blood flow and/or volume may influence the sequences of lung unit recruitment and derecruitment during inflation and subsequent deflation, or the total extent of air-liquid interface in the lungs, but these results also suggest a possible effect of lung blood flow and/or volume on alveolar surfactant activity.

Confirming this hypothesis, Gutierrez et al. [31] found a decrease in surfactant protein expression in lambs with artificially induced increased pulmonary blood flow, suggesting this effect may be due to increased endothelial NO production.

The inspiratory limb of the volume-pressure loop under the BVE condition is shifted to the right with respect to the control condition, mostly at high lung volumes (fig. 4). This is in agreement with previously reported results in isolated cat lungs [32], suggesting that the effects of BVE on respiratory system elastance are more relevant at high lung volumes.

Although quantitatively limited, displacement to the right of the inspiratory pressure-volume curve during BVE contributes an additional increase in $\mathrm{WOB}_{\text {el }}$ for a given VT.

Displacement to the left of the expiratory limb decreases the available elastic pressure during passive expiration (fig. 4).
Our data obtained in normal animals under controlled and minimally invasive conditions confirm that the increase in pulmonary blood flow significantly increases respiratory system elastance and resistance. In addition, an effect on respiratory system hysteresis is demonstrated for the first time.

These changes lead to a significant increase in both $\mathrm{WOB}_{\mathrm{el}}$ and $\mathrm{WOB}_{\text {res}}$, which were measured for the first time at different values of lung blood volume in the positive-pressure inflated respiratory system of the rat.

Thus, respiratory mechanics are significantly influenced as a result of increased cardiac output.

Our measurements of respiratory mechanics were done shortly after BVE.

We have no data describing how long the observed changes may last. This information is rather difficult to obtain because mechanical ventilation per se is known to alter respiratory mechanics with time [22]. We can speculate that the changes in respiratory mechanics we observed progressively decrease with time due to the urinary elimination of the excess of fluid. Svensen et al. [33] reported the rate of elimination of excess of fluid after intravenous hypertonic saline infusion to be about $20 \%$ of volume expansion per hour, and about the same result may be deduced from the data of Tollofsrud et al. [34] after plasma expander infusions. Thus, it may be expected that the mechanical parameters should return to baseline values in no more than $3-4 \mathrm{~h}$. This estimated time seems to be long enough to cause possible deleterious effects in patients receiving large intravenous infusions. Even if the changes in respiratory mechanics we observed are rather small (10-20\%), they are sufficient to significantly increase WOB, hence to cause a potentially harmful effect in severely ill patients, who might undergo respiratory failure.

Our findings suggest important clinical applications. Altered cardiac output is a frequent condition in many different diseases, and an increase in cardiac output may also result from frequently therapeutic manipulations of cardiac function such as acute BVE. The consequences of modifications of respiratory mechanics should be known and considered.

\section{Acknowledgement}

The authors gratefully thank Prof. J. Milic-Emili and Prof. P.E. Di Prampero for their suggestions and for reading the manuscript. 


\section{References}

1 Bancalari E, Jesse M, Gelband H, Garcia O: Lung mechanics in congenital heart disease with increased and decreased pulmonary blood flow. J Pediatr 1977;90:192-195.

$>2$ Davies CJ, Cooper SG, Fletcher ME, Hatch DJ, Helms PJ, Gordon I, Stocks J: Total respiratory compliance in infants and young children with congenital heart disease. Pediatr Pulmonol 1990;8:155-161.

-3 Freezer NJ, Lanteri CJ, Sly PD: Effect of pulmonary blood flow on measurements of respiratory mechanics using the interrupter technique. J Appl Physiol 1993;74:10831088.

4 Lanteri CJ, Kano S, Duncan AW, Sly PD: Changes in respiratory mechanics in children undergoing cardiopulmonary bypass. Am J Resp Crit Care Med 1995;152:18931900.

$>5$ Yau KI, Fang LJ, Wu MH: Lung mechanics in infants with left-to-right shunt congenital heart disease. Pediatr Pulmonol 1996;21:4247.

6 Baraldi E, Filippone M, Milanesi O, Magagnin G, Vencato F, Barbieri P, Pellegrino PA, Zacchello F: Respiratory mechanics in infants and young children before and after repair of left-to-right shunts. Pediatr Res 1993;34:329-333.

7 Stayer SA, Diaz LK, East DL, Gouvion JN, Vencill TN, McKenzie ED, Frazer CD, Andropoulos DB: Changes in respiratory mechanics among infants undergoing heart surgery. Anesth Analg 2004;98:49-55.

$>8$ Greenspan JS, Davis DA, Russo PA, Wolfson $\mathrm{MR}$, Shaffer TH: Operative creation of left to right cardiac shunts: pulmonary function sequelae. Ann Thorac Surg 1993;55:927-932.

$\checkmark 9$ Habre W, Schutz N, Pellegrini M, Beghetti M, Sly PD, Hantos Z, Petak F: Preoperative pulmonary hemodynamics determines changes in airway and tissue mechanics following surgical repair of congenital heart didease. Pediatr Pulmonol 2004;38:470476.

10 Schindler MB, Bohn DJ, Bryan AC, Cutz E, Rabinovitch M: Increased respiratory system resistance and bronchial smooth muscle hypertrophy in children with acute postoperative pulmonary hypertension. Am J Respir Crit Care Med 1995;152:1347-1352.
11 Wildhaber JH, Uhlig T, Sly PD: Partitioning of alterations in pulmonary mechanics due to vascular engorgement in piglets. Pediatr Pulmonol 1998;25:45-51.

12 Bates JHT, Rossi A, Milic-Emili J: Analysis of the behavior of the respiratory system with constant inspiratory flow. J Appl Physiol 1985;58:1840-1848.

13 Bates JHT, Baconnier P, Milic-Emili J: A theoretical analysis of interrupter technique for measuring respiratory mechanics. J Appl Physiol 1988;64:2204-2214.

14 D’Angelo E, Calderini E, Torri G, Robatto M, Bono D, Milic-Emili J: Respiratory mechanics in anesthetized paralyzed humans: effects of flow, volume, and time. J Appl Physiol 1989;67:2556-2564.

15 Coussa ML, Guérin C, Eissa NT, Corbeil C, Chassé M, Braidy J, Matar M, Milic-Emili J: Partitioning of work of breathing in mechanically ventilated COPD patients. J Appl Physiol 1993;75:1711-1719.

16 Saldiva PHN, Cardoso WV, Caldeira MPR, Zin WA: Mechanics in rat by end-inflation occlusion and single-breath methods. J Appl Physiol 1987;63:1711-1718.

17 Cardoso WV, Saldiva PHN, Criado, PMP, Sakae RS, Bohm GM: A comparison between the isovolume and the end-inflation occlusion methods for measurements of lung mechanics in the rat. J Appl Toxicol 1991;11: 79-84.

18 Reta GS, Riva JA, Piriz H, Medeiros AS, Rocco PMR, Zin WA: Effects of halothane on respiratory mechanics and lung's hystopathology in normal rats. Br J Anaesth 2000;84: 372-377.

19 Buzello W, Diefenbach C, Nigrovic W: Muscle relaxants: a clinical update. Acta Anaesthesiol Scand Suppl 1996;109:165-167.

20 Truwit JD, Marini JJ: Evaluation of thoracic mechanics in the ventilated patients. 2. Applied mechanics. J Crit Care 1988;3:199213.

21 Bates JH, Hunter IW, Sly PD, Okubo S, Filiatrault S, Milic-Emili J: Effect of valve closure time on the determination of respiratory resistance by flow interruption. Med Biol Eng Comput 1987;25:136-140.

22 Dellacà RL, Zannin E, Sancini G, Rivolta I, Leone BE, Pedotti A, Miserocchi G: Changes in the mechanical properties of the respiratory system during the development of interstitial lung edema. Resp Res 2008;9:51-57.
23 Rubini A, Bondì M: Effect of the oestral cycle on respiratory mechanics in the rat. Acta Physiol 2007;189:379-383.

24 Rubini A, Bondì M: Variations of respiratory mechanics in the rat during the day. Biol Rhythm Res 2008;39:397-404.

25 Peratoner A, Nascimento CS, Santana MCE, Cadete RA, Negri EM, Gullo A, Rocco PRM, Zin WA: Effects of propofol on repiratory mechanics and lung hystology in normal rats. Br J Anaesth 2004;92:737-740.

-26 Pellegrino R, Dellacà R, Macklem PT, Alivert A, Bertini s, Lotti P, Agostoni PG, Locatelli A, Brusasco V: Effects of rapid saline infusion on lung mechanics and airway responsiveness in humans. J Appl Physiol 2003;95:728-734.

27 Crosfill ML, Widdicombe JG: Physical characteristics of the chest and lungs and the work of breathing in different mammalian species. J Physiol 1961;158:1-14.

28 Hordof AJ, Mellins RB, Gersony WM, Steeg $\mathrm{CN}$ : Reversibility of chronic obstructive airways disease in infants following repair of ventricular septal defects. J Pediatr 1977;90: 187-191.

29 Shardonofsky FR, Sato J, Bates JHT: Quasistatic pressure-volume hysteresis in the canine respiratory system in vivo. J Appl Physiol 1990;69:2230-2236.

30 Rubini A, Catena V, Parmagnani A, Morè C, Del Monte D: Pulmonary vascular engorgement increases hysteresis in the rat's lungs. Acta Physiol Scand 2006;188:076.

31 Gutierrez JA, Parry AJ, McMullan DM, Chapin CJ, Fineman JR: Decreased surfactant proteins in lambs with pulmonary hypertension secondary to increased blood flow. Am J Physiol Lung Cell Mol Physiol 2001;281:L1264-L1270.

32 Frank NR: Influence of acute vascular congestion on recoiling force of excised cat's lung. J Appl Physiol 1959;14:905-908.

-33 Svensen CH, Waldrop KS, Edsberg L, Hahn RG: Natriuresis and the extracellular volume expansion by hypertonic saline. J Surg Res 2003;113:6-12.

-34 Tollofsrud S, Elgjo GI, Prough DS, Williams CA, Traber DL, Kramer GC: The dynamics of vascular volumes and fluid shifts of lactated Ringer's solution and hypertonic-saline-dextran solutions infused in normovolemic sheep. Anesth Analg 2001;93: 823-831. 